\title{
Ireland reviews water fluoridation
}

I reland has launched an extensive review of water fluoridation amid ongoing public resistance to the 50 -year-old practice. The review by Ireland's Health Research Board, a government agency, will examine the latest national and international studies to assess the safety and effectiveness of water fluoridation.

It comes as anti-fluoride campaigns continue to surface across this country of 4.5 million, particularly in County Cork, where 48 county councillors have unanimously called for an immediate end to the practice.

Critics draw links between water fluoridation and a variety of health problems, and argue the practice deprives them of their right to choose whether to ingest the substance. But Ireland's Expert Body on Fluorides and Health, a committee of scientists that reviews emerging research and advises the health minister, insists that water fluoridation at recommended levels is safe and effective. Halting the practice could have serious consequences in Ireland, where dietary habits put the public at unusually high risk of tooth decay, they say.

"We are sure it will lead to an increase in oral disease," says Joe Mullen, Ireland's chief dental inspector and a former member of the committee. "We are absolutely certain of that. It's not a case of a theoretical possibility that this might cause harm."

Ireland began adding fluoride to the public water supply in 1964 . The country now has one of the widest distributions of fluoridated water, covering $73 \%$ of the population. But the practice is rare in the rest of Europe, with only the United Kingdom and Spain supplying fluoride through water, in each case to about $10 \%$ of their populations. Low levels of fluoridation in Europe have added even more fuel to the opposition in Ireland.

"For me it's two things: first it's the improper use of the public water supply to medicate the masses, and second, there is enough scientific doubt about its effects," says Christopher O'Sullivan,

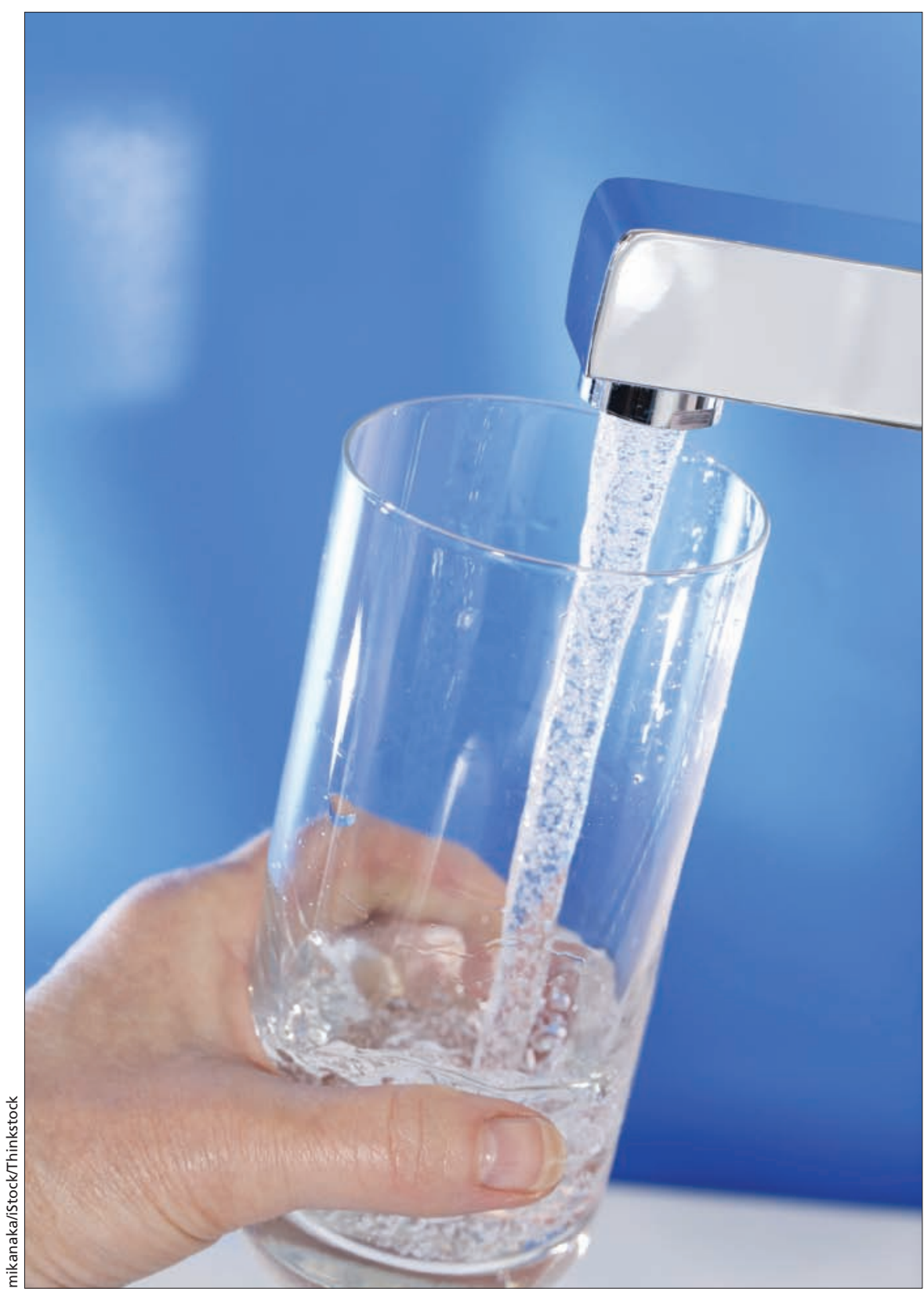

In County Cork, 48 councillors have called for an immediate end to water fluoridation.

a councillor in County Cork. "There should be a choice."

Critics worry about what they say are connections between fluoride and health issues, including cancer, reduced bone density and lower IQs in children.

A much-debated systematic review and meta-analysis published in 2012 summarized the findings of 27 studies on intelligence tests in fluoride-exposed children, 25 of which were carried out in China. All but one documented an IQ deficit associated with increased fluoride exposure.

The results did not, however, allow for any judgment to be made about the recommended levels of fluoridation in the United States — 0.7-1.2 parts per 
million, lower than in ground water in some cases - according to Dr. Philippe Grandjean, one of the paper's authors and an adjunct professor of environmental health at the Harvard School of Public Health in Boston.

"On the other hand, neither can it be concluded that no risk is present," because no studies have been done on the effects of fluoridation on IQ at US levels, Grandjean wrote in an email.

The recommended level in Irish drinking water is $0.6-0.8$ parts per million, with a target of 0.7 .

Ireland's expert body reviewed the same 25 Chinese studies but, because they frequently didn't state the fluoride concentration or account for factors such as pollution and socioeconomic status, it wasn't possible to draw any conclusions, says Mullen. The World Health Organization also reviewed the potential link between fluoridated water and IQ deficits, but found the weight of the evidence to be inadequate.

The WHO, Centers for Disease Control and Prevention, the Irish Dental Association, and the World Dental Federation all endorse fluoridation as a safe way to combat tooth decay. And last week, a report by Public Health England found no evidence of harm from fluoridated water and no difference in the rates of hip fracture, Down syndrome, osteosarcoma or other cancers between people in fluoridated and non-fluoridated areas.

"It's safe, it's effective and it's cost effective," says Sean Malone, president of the Irish Dental Association. "People don't realize the benefits of fluoride in this country."

Still, antifluoride advocates remain skeptical. "I don't think it's the cause of all evil, but I think there's enough concern to warrant a cautionary stance," said Hannah Dare, who installed a filter to remove fluoride from the water at her café in Bantry, a town in West Cork.

Dare would like to see more education for children on how to care for their teeth. As in other European countries, fluoride could be delivered through toothpaste, salt and supplements, she says.

But few European countries are at the same risk for tooth decay as Ireland, says Denis O'Mullane, chair of the committee that reviews fluoride research for Ireland's expert body. Ireland scored above the European average when it came to the consumption of sweets and posted the highest consumption of cakes and biscuits in Europe, according to a 2010 Eurobarometer report on oral health.

"Studies basically show that our dietary habits make us more prone to decay than other countries,' says O'Mullane. _ Naomi Powell, Dublin, Ireland

CMAJ 2014. DOI:10.1503/cmaj.109-4781 